\title{
Finite Element Modelling of Reinforced Concrete Beam Strengthened with Embedded Steel Reinforcement Bars
}

\author{
Nurman Chandra, Ridwan* (1), Muhammad Ikhsan \\ Civil Engineering Department, Universitas Riau, Pekanbaru, Indonesia
}

\begin{abstract}
The increased of loads on existing reinforced concrete infrastructure and the lack of initial design and construction will induce flexural and shear failure. Several methods have been introduced to increase the shear capacity of existing reinforced concrete elements with FRP, involving the use of plates or fabric externally bonded (EB) to the webs of the bridge beams, prestressed straps wrapped around the beams or bars mounted within grooves prepared in the near-surface mounted (NSM) technique. Typical Indonesian concrete bridges consisted main girders connected with diaphragm beams where the distance between those girders are very close. In particular case, where the webs of the beams are difficult to access, a novel approach is introduced, namely deep embedment (DE) method. Three reinforced concrete beam models were prepared for this study. One specimen was the control specimen and identified as Beam-CS while other two were the strengthened specimens and identified as Beam-SS-3EB and Beam-SS-5EB. All specimens have the same dimensions and reinforcement configurations. Specimen Beam-SS-3EB and Beam-SS-5EB was strengthened using different amount of additional shear reinforcement. Specimen Beam-SS-3EB was strengthened with three rows of $6 \mathrm{~mm}$ embedded plain steel bars while specimen Beam-SS-5EB was strengthened with five rows of $6 \mathrm{~mm}$ plain steel bars. During analysis, the maximum reaction force and the displacement at loading point as well as the stress of bottom reinforcement were reported. The results showed that element size significantly affected the load-displacement curve behaviour. The similarity of the hysteresis curve in the FE analysis using the $25 \mathrm{~mm}$ element size suggested a reasonably good agreement between the analytical calculation and the prediction result from the FE analysis. Furthermore, maximum reaction force for Beam-SS-3EB and Beam-SS-5EB were $30.30 \mathrm{kN}$ and $31.77 \mathrm{kN}$, respectively, represent an increase of $17.67 \%$ and $23.29 \%$ compared to that of the Beam-CS.
\end{abstract}

Key words: Finite Element Model, Reinforced Concrete Beam, Strengthening, Deep Embedment Method

\section{INTRODUCTION}

The increased of loads on existing reinforced concrete infrastructure and the lack of initial design and construction will induce flexural and shear failure. Typical Indonesian concrete bridges consisted main girders connected with diaphragm beams where the distance between those girders are very close. UK Network Rail conducted analytical assessments based on the truss analogy and the results have demonstrated an apparent shear deficiency in these bridges, and therefore it is necessary to ensure that a practical shear-strengthening scheme is available.

Several methods have been introduced to increase the shear capacity of existing reinforced concrete elements with FRP, involving the use of plates or fabric externally bonded (EB) to the webs of the bridge beams, prestressed straps wrapped around the beams or bars mounted within grooves prepared in the near-surface mounted (NSM) technique.

Since twenty years ago, strengthening of reinforced concrete structure element by using externally bonded (EB) fibre-reinforced polymer (FRP) composites has gained its popularity amongst the construction engineering community. Researches to study different aspects on the use of EB strengthening method followed the successful of application of EB in the field of strengthening and rehabilitation works involving $\mathrm{RC}$ beams and girders. In practice, the shear capacity of RC beams was increase by bonding FRP sheets on the side surface of the beams to be strengthened. Experimental research studies confirmed that the shear capacity of RC beams strengthened with EB FRP method can be enhanced $[1,2,3]$. On the other hand, this method showed several drawbacks as: (1) the strength of concrete at surface is low; (2) surface preparation is tedious; (3) prone to vandalism/fire; and (4) the existence of debonding between the concrete and FRP. Another strengthening method called near-surface mounted (NSM) FRP rebar method was introduced by De Lorenzis and Nanni [4]. To strengthened RC elements, FRP rods are placed into grooves prepared on the concrete cover of each side faces and the researches has confirmed that NSM strengthening method increase shear resistance of RC beams $[4,5]$. However, debonding of FRP rods from the concrete is still exist and conclude that the debonding problem remains the main disadvantage for EB FRP and NSM methods. The relatively low tensile strength of the concrete surface limits the bonding force between the FRP and concrete [6] and trigger premature debonding of the FRP.

$\begin{array}{ll}\text { Received } & \text { : August 12,2019 } \\ \text { Revised } & \text { : August 23, 2019 } \\ \text { Accepted } & \text { : August 25, 2019 }\end{array}$


In particular case, where the webs of the beams are difficult to access, a novel approach is introduced. In this method, holes are drilled into the beams in the area need to be strengthened and then the holes are filled by injecting high-viscosity epoxy resin to bond between the concrete and the inserted bars. This technique is knows as embedded through section (ETS) method or deep embedment (DE) method. The experimental results showed that this strengthening technique had potential to enhance shear capacity of reinforced concrete elements $[7,8]$. The application of DE method in strengthening of shear deficient reinforced concrete beam-column joints is also confirmed. The strengthened specimen had higher peak-to-peak stiffness, displacement ductility and energy dissipation capacity. Furthermore, the joint shear strength of specimens strengthened with embedded bars was enhanced 6-21\% compared with the control specimen $[9,10]$.

\section{Research Significance}

The conventional strengthening methods (e.g. EB and NMS method) for reinforced concrete deficient in shear, although efficient to some extent, present numerous shortcomings. Debonding, tedious surface preparation, and the need for protection against vandalism and fire are evidence that proves of these short-comings while the novel strengthening method, DE method, is less time consuming, needs less adhesive, and does not require surface preparation or skilled workers to install. Several studies had been conducted to study the behaviour of beams strengthened with EB FRP sheets [11]. Hence, the aim of this research is to conduct numerical study to investigate behaviour of reinforced concrete beam strengthened with embedded steel bars. To this end, a finite element (FE) model has been developed and validated against analytical results calculated using sectional analysis using Response-2000 software [12].

\section{MATERIALS AND METHODS}

\subsection{Description of Specimens}

Three reinforced concrete beam models are prepared for this study. One specimen is the control specimen and identified, as Beam-CS and the other two are the strengthened specimens and identified as Beam-SS-3EB and Beam-SS-5EB. All specimens have the same dimensions and reinforcement configuration. The cross sections of beams are $150-\mathrm{mm}$ width and $250-\mathrm{mm}$ depth. The beam has overall length of 2000-mm. The beams are reinforced with $26-\mathrm{mm}$ plain steel bars for top longitudinal reinforcement and 2 12-mm plain steel bars for bottom longitudinal reinforcement. These beams have only one close stirrup located at a distance of $600-\mathrm{mm}$ from supports. To avoid stress concentration due to support reaction, three closed stirrups are installed on each support. Reinforcement details for control specimen are depicted in Figure 1a.

The specimens Beam-SS-3EB and Beam-SS-5EB are the strengthened specimens. The specimens are strengthened with deep embedment method. Specimen Beam-SS-3EB is reinforced with three rows of $6 \mathrm{~mm}$ plain steel bars and the distance of each rows of embedded bars is $200 \mathrm{~mm}$. While specimen Beam-SS-5EB is reinforced with five rows of $6 \mathrm{~mm}$ plain steel bars and the distance of each rows of embedded bars is $100 \mathrm{~mm}$. Reinforcement configuration for strengthened specimens can be seen in Figure $1 b$ and $1 c$.

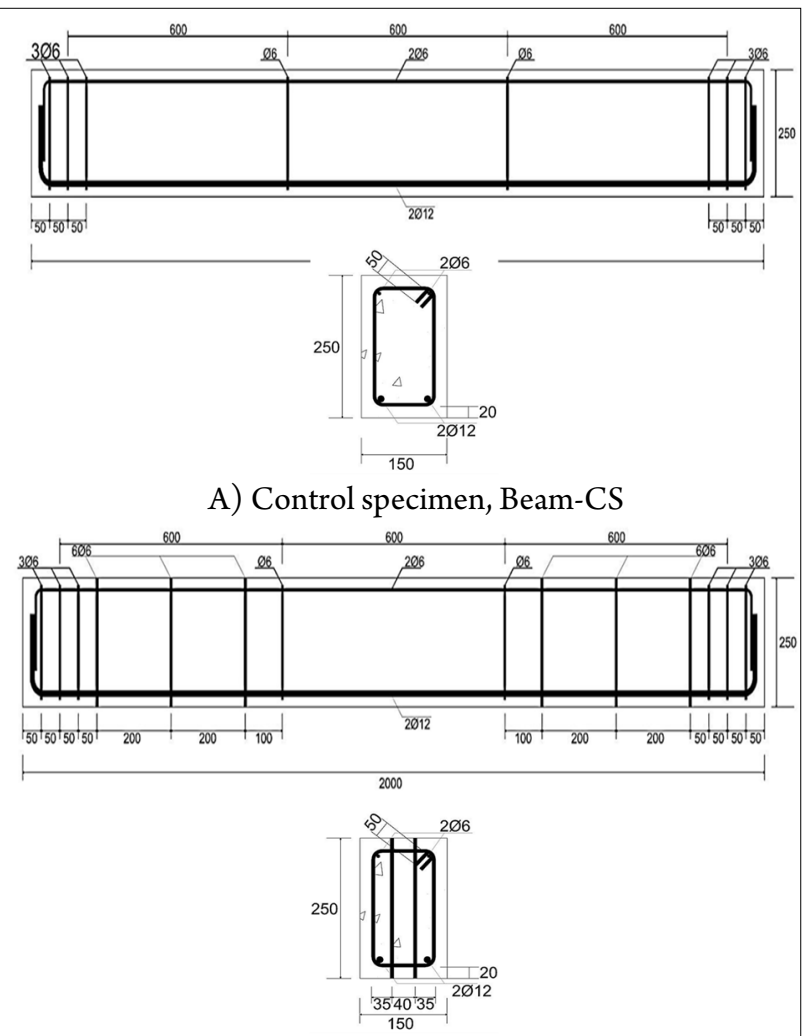

B) Specimen strengthened with three rows embedded bars, Beam-SS-3EB

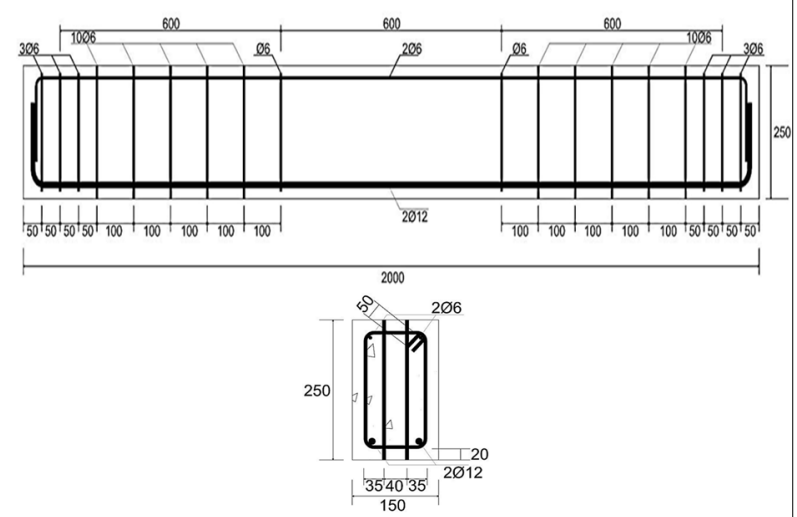

C) Specimen strengthened with five rows embedded bars, Beam-SS-5EB

Fig. 1. Reinforcement details for specimens, units in $\mathrm{mm}$

\subsection{Materials}

Table 1 Mechanical properties of reinforcement bars

\begin{tabular}{|c|c|c|c|c|}
\hline No & $\begin{array}{c}\text { Bar } \\
\text { Diameter } \\
(\mathrm{mm})\end{array}$ & $\begin{array}{l}\text { Yield } \\
\text { Strength } \\
(\mathrm{MPa})\end{array}$ & $\begin{array}{l}\text { Ultimate } \\
\text { Strength } \\
(\mathrm{MPa})\end{array}$ & Remark \\
\hline 1 & 6 & 384.5 & 503 & top reinforcement bars \\
\hline 2 & 12 & 352.0 & 527 & bottom reinforcement bars \\
\hline 3 & 6 & 379.4 & 500 & $\begin{array}{l}\text { shear reinforcement for } \\
\text { closed stirrup and } \\
\text { embedded bars }\end{array}$ \\
\hline
\end{tabular}


The concrete strength for all specimens are $20 \mathrm{MPa}$. The bottom longitudinal reinforcement has a nominal yield and ultimate strength of $352 \mathrm{MPa}$ and $527 \mathrm{MPa}$, respectively while the top longitudinal reinforcement has a nominal yield and ultimate strength of $384.5 \mathrm{MPa}$ and $503 \mathrm{MPa}$, respectively. The shear reinforcement has a nominal yield and ultimate strength of $379.4 \mathrm{MPa}$ and $500 \mathrm{MPa}$, respectively.

\subsection{Material Behaviour Concrete}

ABAQUS has several constitutive models to describe the behaviour of plain concrete subjected to varying conditions of loading. They are including the Smeared Crack model, the Brittle Cracking model and the Concrete Damage Plasticity (CDP) model. The smeared Crack model is used to simulate the response of reinforced or unreinforced concrete under low confining pressure subjected to monotonic loading. On the other hand, the Brittle Crack model can only be used when the compressive response is assumed to be elastic and the only source of material nonlinearity is tensile cracking. Lastly, the CDP model can be used to simulate the cyclic response of concrete when damage in both tension and compression is existing and this model was adopted in this study.

The CDP model is developed according the yield functions suggested by Lubliner et al. [13] and modified by Lee and Fenves [14]. This model combines isotropic damage plasticity with hardening plasticity concepts. Two distinct material modes, namely concrete crushing and concrete cracking are accounted for. The evolution of concrete damage (i.e. evolution of failure surface in the strain space) in this material model is traced by tensile and compressive equivalent plastic strains that are linked to tension and compression failure respectively. The CDP model is explained in detail in the ABAQUS Documentation [15].

\section{Concrete Under Compressive Load}

In this study, stress-strain behaviour for concrete under compression is defined in three different regions, namely elastic, hardening, and softening. A concrete response in linear-elastic is considered between $30-40 \%$ of its ultimate compressive strength. When the compression load is increased, the hardening region of the stress-strain curve develops where the concrete stress increases until it reaches maximum compressive strength and the tangential stiffness decreases to zero. After the ultimate compressive stress is reached, the softening region of the concrete in compression starts. This is the part of the stress-strain curve where the strength of concrete degrades rapidly and concrete softens whilst losing its load carrying capacity.

The stress-strain relationship of concrete compressive load employed in this study is shown in Figure 2. Part 1 in Figure 2 is the elastic part of the concrete stress- strain behaviour and can be computed by using Equation (1):

$$
\sigma_{c(1)}=E_{c} \times \varepsilon_{c}
$$

\section{where}

$\sigma_{c(1)}$ is the concrete stress in elastic region, $\mathcal{E}_{c}$ is the concrete strain in elastic region, and $E_{c}$ is the concrete modulus of elasticity. In this study, the concrete modulus elasticity is calculated using the formula proposed by Carreira and Chu [16]:

$$
E_{c}=3320 \times\left(f_{c}^{\prime}\right)^{0.5}+6900
$$

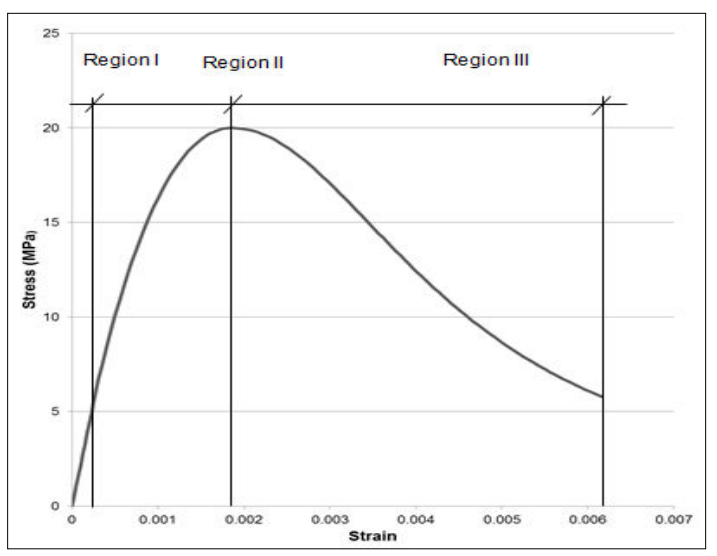

Fig. 2. Stress-strain relationship of concrete under compression

Part 2 is the hardening region where the stress is still in the ascending branch up to the peak load of concrete strength $f_{c m}$ at $\mathcal{E}_{c 1}$. The stress-strain relationship of the concrete curve on this part is calculated by using the expression suggested in CEB-FIP Model Code 1990 [17]:

$$
\sigma_{c(2)}=\frac{E_{c i} \frac{\varepsilon_{c}}{f_{c m}}-\left(\frac{\varepsilon_{c}}{\varepsilon_{c i}}\right)^{2}}{1+\left(E_{c i} \frac{\varepsilon_{c}}{f_{c m}}-2\right) \frac{\varepsilon_{c}}{\varepsilon_{c i}}} f_{c m}
$$

where

$\sigma_{c(2)}$ is the concrete stress in region $2, f_{c m}$ is the mean compressive strength, $\mathcal{E}_{c}$ is the concrete strain in elastic region, $\mathcal{E}_{\mathrm{c}}$ is the concrete strain at peak stress, and $E_{c i}$ is the secant modulus from the origin to the peak compressive stress. A formula suggested by Kratzig and Polling [18] was used to calculate the secant modulus.

$$
E_{c i}=\frac{1}{2 E_{c}}\left(\frac{f_{c m}}{\varepsilon_{c}}\right)^{2}-\frac{f_{c m}}{\varepsilon_{c}}+\frac{3}{2} E_{c}
$$

For the practical use, the concrete strain at peak stress $\mathcal{E}_{\mathrm{d}}$ can be taken as 0.002 [19]. In this study, this value was calculated using the formula proposed by Carreira and Chu [16].

$$
\begin{gathered}
\varepsilon_{c i}=\frac{f_{c m}}{E_{c}}\left(\frac{r}{r-1}\right) \\
r=\frac{f_{c m}}{17}+0.8
\end{gathered}
$$

Part 3 is the softening branch of the concrete stress-strain relationship. This part is identified by the existence of damage localization when peak concrete compression strain is exceeded. The definition of the softening branch depends on the fracture energy dissipated 
through damage, the material parameters and characteristic length $I_{e q}$ Bažant and $\mathrm{Oh}$ [20] of the concrete volume studied. The concept of fracture energy was initially accepted for tension cracks in Kratzig and Polling [18] and was introduced for softening under compression by Feenstra [21]. The fracture energy under compression is termed "crushing energy $\left(G_{c i}\right)$ " to differentiate it with the term of fracture energy under tension. As a result, the following formula was used to calculate the stress-strain relationship on Part 3,

$$
\sigma_{c(3)}=\left(\frac{2+\gamma_{c} f_{c m} \varepsilon_{c 1}}{2 f_{c m}}-\gamma_{c} \varepsilon_{c}+\frac{\gamma_{c} \varepsilon_{c}^{2}}{2 \varepsilon_{c 1}}\right)^{-1}
$$

$\gamma_{c}$ is the only parameter that controls the area under the stress-strain curve.

$$
\gamma_{c}=\frac{\pi^{2} f_{c m} \varepsilon_{c}}{\left[\frac{G_{c l}}{l_{e q}}-\frac{1}{2} f_{c m}\left(\varepsilon_{c 1}(1-b)+b \frac{f_{c m}}{E_{c}}\right)\right]^{2}}
$$

where:

$G_{c i}$ is the localized crushing energy, $l_{e q}$ is the characteristic length of the respective $\mathrm{FE}$ integration point, $\mathrm{b}$ is a material parameter with a value $0<\mathrm{b} \leq 1$, and is suggested to be 0.7 as it fits well with the experimental data of concrete under cyclic load test Birtel and Mark [22]. Element character length should be limited to

$$
l_{e q} \leq \frac{G_{c l}}{f_{c m}\left(\varepsilon_{c}(1-b)+b \frac{f_{c m}}{\varepsilon_{c}}\right)}
$$

Concrete under Tensile Load

The stress-strain curve of concrete under tension load is also modelled in a similar manner to the compressive stress-strain curve. In this case, the stress-strain curve for concrete under tension shows two distinct regions, namely the elastic region and the softening region as shown in Figure 3.

The elastic region where the stress and strain relationship is linier is defined by Equation (10)

$$
f_{c t}=E_{c} \varepsilon_{c r}
$$

where

$\mathcal{E}_{c t}$ is the cracking strain, $f_{c t}$ is the tensile strength of concrete. In this study, the tensile strength of concrete is calculated using equation (11).

$$
f_{c t}=0.3 \times\left(f_{c m}\right)^{\frac{2}{3}}
$$

For softening part, response of concrete in tension initiates upon the attainment of the concrete tensile strength and it can be modelled to be linear or exponential. In this study, Equation (12) developed by Kratzig and Polling [18] is used to define this region.

$$
\sigma_{(\varepsilon)}=f_{c t} \times e^{\left(\frac{\varepsilon_{c r}-\varepsilon}{\gamma_{t}}\right)}
$$

where

$\mathcal{E}$ is concrete strain under tension and $\gamma_{t}$ is the parameter that controls the area under stress- strain curve. The post-peak curve mainly depends on the fracture energy $G_{f}$ and the equivalent length $l_{e q}$.

$$
\gamma_{t}=\frac{G_{f}}{l_{e q} f_{c t}}-\frac{1}{2} \frac{f_{c t}}{E_{c}}
$$

Where $G_{f}$ is the fracture energy

The fracture energy $G_{f}$ is the most important aspect of tension stiffening and generally small differences are observed when using different expressions to describe the tension stiffening response.

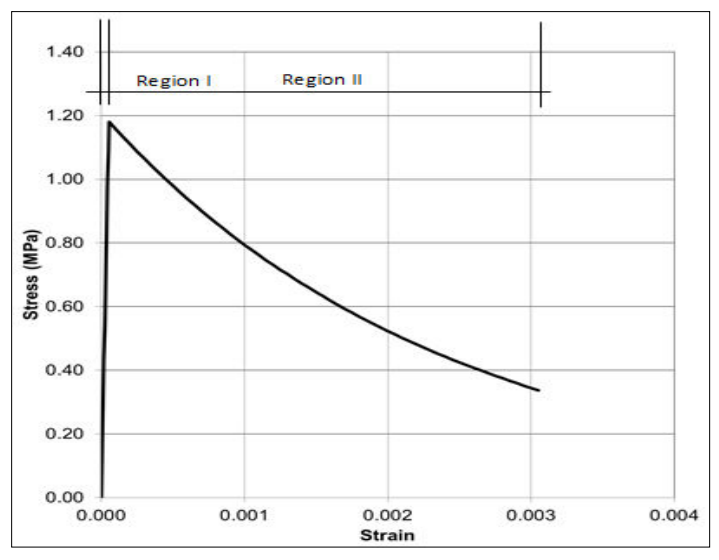

Fig. 3. Stress-strain relationship of concrete under tension

\section{Steel Reinforcing Bars}

The von Mises yield criterion in conjunction with isotropic hardening response was employed to describe the material response of reinforcing steel beyond its yield point. Up to yield, the steel was assumed linear elastic, with a Young's modulus equal to $200 \mathrm{GPa}$ and a Poisson ration equal to 0.3 The reinforcement properties, namely yield stress, ultimate stress and modulus of elasticity, were defined from tensile testing stress-strain data, and a trilinear elastic-plastic-linear hardening engineering stress-strain curve was defined as shown in Figure 4.

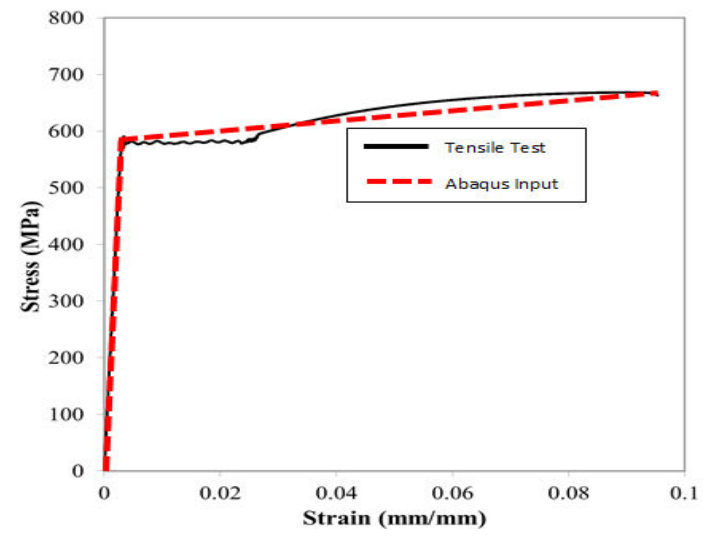

Fig. 4. Stress-strain model of steel reinforcement prepared for ABAQUS model

\subsection{Boundary Conditions and Constraints}

Three-dimensional nonlinear finite element model was developed with respect to the reference reinforced concrete 
beam model shown in Figure 1. Tie constraints were employed to connect the degrees of freedom of the support and loading plates to the corresponding degrees of freedom of reinforced concrete beam element. The degrees of freedom of the truss elements simulating the embedded reinforcing bars and the degrees of freedom of the brick elements of the surrounding concrete was tied using embedded region constraint. A constant compressive force was imposed at a reference point and tied to the loading plate that connected to the beam element in the form of a prescribing displacement history. FE model developed in this study can be seen in Figure 5.

The convergence difficulties particularly existed when concrete cracking exists are difficult to avoid in the nonlinear $\mathrm{FE}$ analysis. To overcome this issue, ABAQUS EXPLICIT solver was chosen during the analysis. ABAQUS EXPLICIT is an $\mathrm{FE}$ code that adopts an explicit time integration scheme to solve the equations of dynamic equilibrium of highly nonlinear problems. Instead of calculating the element matrices, assembling the global matrix of the structure, and solving a large system of equations by inverting the global matrix, ABAQUS EXPLICIT performs equilibrium calculations at each node. The explicit solver algorithm is known for its reliability, which means that the number of time increments employed is determined from the maximum stable time increment.

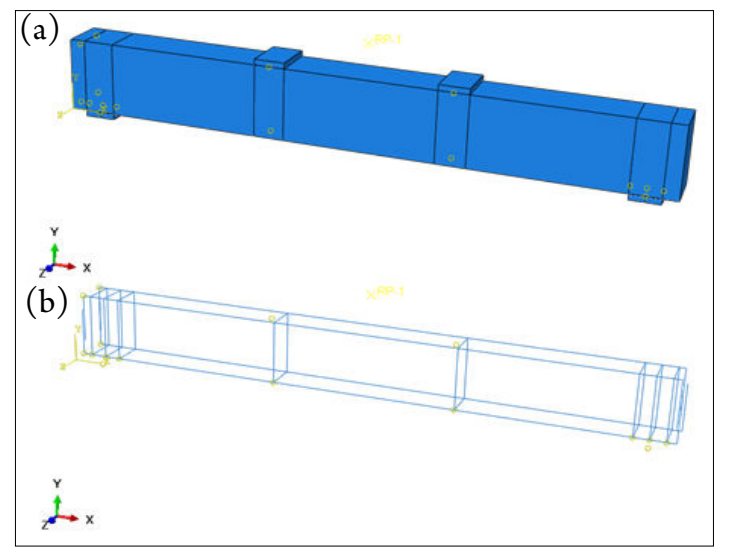

Fig. 5. Finite elemen model for (a) solid element, (b) truss element

\subsection{Concrete Beam and Loading Plate Model}

The $3 \mathrm{D}$ geometry of the concrete beam and the loading plates as well as support plate were idealised with solid elements. The ABAQUS element library contains several types of 3D solid elements, including linear and quadratic elements in hexahedral, tetrahedral or wedge geometries, which can be used to approxime the displacement field of the model with various degrees of accuracy and varying computational costs.

Among the available 3D linear elements, the linear tetrahedral elements are not able to capture strain/stress gradient within the element so that the use of very fine mesh and higher order elements is a must. It is suggested that linear tetrahedral elements are only used when geometric versatility is important. Hence, the 8-node linear brick element with reduced integration (C3D8R) and hourglass control was chosen as the most appropriate one [23]. C3D8R element type was successfully implemented in modelling RC concrete element subjected to reversal cyclic loading in Danesh et al. [24] and Abbas et al. [25]. These first order brick elements have three translational degrees of freedom at each node, as shown in Figure 6, and allow for trilinear stress variations.

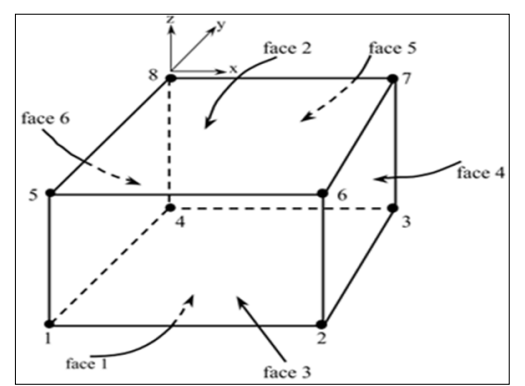

Fig . 6. Eight-node brick element

\subsection{Reinforcement Bar Model}

Element types available in ABAQUS and can be used to model reinforcement steel bars, namely truss elements (T3D2), linear beam elements (B31) and quadratic beam elements (B32). The two-node T3D2 element allows constant axial stress along its length and has no stiffness when subjected to loading perpendicular to the axis of the element. On the other hand, beam elements B31 and B32 are Timoshenko beam elements resulting in axial, shear and flexural stiffness. B32 uses quadratic interpolation functions for position and displacement whilst B31 is a $3 \mathrm{D}$ linear Timoshenko beam element. The three elements mentioned, their associated notes and geometry are shown in Figure 7.

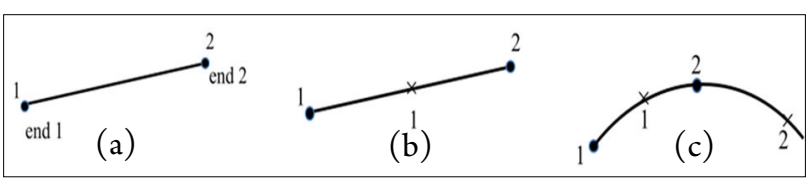

Fig. 7. Elements to model reinforcement available in ABAQUS

Gebreyohaness [23] has conducted detailed analysis to determine proper type of element to model reinforcing bars. The results showed that T3D2, B31 and B32 element types did not significantly affect the accuracy of the results. On the other hand, the use of beam elements resulted in higher computational cost compared to the truss elements. Hence the T3D2 truss element is used to model reinforcement bar throughout this study.

\section{RESULTS AND DISCUSSION}

\subsection{Mesh Sensitivity and Validation}

A suitable mesh size element and appropriate material parameters is examined through a mesh convergence studies to achieve results that has close agreement with the analytical observed response. Three element sizes, namely $100 \mathrm{~mm}, 50 \mathrm{~mm}$ and $25 \mathrm{~mm}$, were initially adopted as a uniform mesh size; the results obtained for each mesh size are presented in Figure 8 in terms of the obtained load-displacement response of the control specimen (Beam-CS). Figure 8 shows that the element size significantly affects the hysteresis curve behaviour. The results presented in Figure 8 (using $25 \mathrm{~mm}$ element size) 
showed a closer agreement with the analytical results in terms of the peak load than those using $100 \mathrm{~mm}$ and $50 \mathrm{~mm}$ element size. The similarity of the hysteresis curves suggested a reasonably good agreement between the analytical observation and the prediction result gained from $\mathrm{FE}$ analysis using $25 \mathrm{~mm}$ element size.

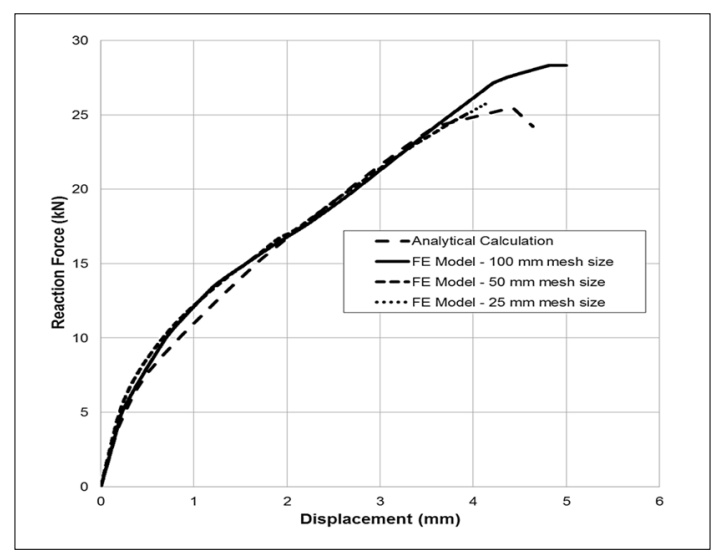

Fig. 8. Comparison of load-displacement response of FE with analytical calculation.

Table 2 Comparison of finite element and analytical study for Beam-CS

\begin{tabular}{lcccc}
\hline & $\begin{array}{c}\mathrm{P}_{\max } \\
(\mathrm{kN})\end{array}$ & $\begin{array}{c}\text { Displacement } \\
(\mathrm{mm})\end{array}$ & $\begin{array}{c}\text { Load } \\
\text { Ratio }\end{array}$ & $\begin{array}{c}\text { Difference } \\
(\%)\end{array}$ \\
\hline $\begin{array}{l}\text { Analytical } \\
\text { Calculation }\end{array}$ & 25.48 & 4.42 & & \\
$\begin{array}{l}\text { FE Model-100 } \\
\text { mm mesh size }\end{array}$ & 28.33 & 4.90 & 1.11 & 11.18 \\
$\begin{array}{l}\text { FE Model-50 } \\
\text { mm mesh size }\end{array}$ & 23.39 & 3.48 & 0.92 & 8.19 \\
$\begin{array}{l}\text { FE Model-25 } \\
\text { mm mesh size }\end{array}$ & 25.75 & 4.14 & 1.01 & 1.05 \\
\hline
\end{tabular}

The load ratio and diffrence of FE analysis to analytical calculation using a $25 \mathrm{~mm}$ element size was 1.01 and $1.05 \%$, while ratios and diffrences using $50 \mathrm{~mm}$ and $100 \mathrm{~mm}$ element size were 0.92 and $8.19 \%$ and 1.11 and $11.18 \%$, respectively. Table 2 shows that the FE analysis conducted on the $25 \mathrm{~mm}$ element size provided a very close agreement between the analytical and the numerical response of the peak load $\left(\mathrm{P}_{\max }\right)$. Based on these observations, further validation is conducted based on the analysis using $25 \mathrm{~mm}$ element size.

\subsection{Effect of Embedded Steel Bars on the Strengthened Beams}

Table 3 Comparison of load-displacement response of control specimen and strengthened specimens

\begin{tabular}{lcccc}
\hline & $\begin{array}{c}\mathrm{P}_{\max } \\
(\mathrm{kN})\end{array}$ & $\begin{array}{c}\text { Displacement } \\
(\mathrm{mm})\end{array}$ & $\begin{array}{c}\text { Load } \\
\text { Ratio }\end{array}$ & $\begin{array}{c}\text { Difference } \\
(\%)\end{array}$ \\
\hline Beam-CS & 25.75 & 4.14 & & \\
Beam-SS-3EB & 30.30 & 5.00 & 1.18 & 17.67 \\
Beam-SS-5EB & 31.77 & 6.00 & 1.23 & 23.39 \\
\hline
\end{tabular}

Figure 9 depicts the load-displacement responses of the strengthened specimen, Beam-SS-3EB and Beam-SS-5EB, compared with the control specimen Beam-CS. Overall, the maximum reaction force for both strengthened beams were enhanced with the increase of number of embedded bars used in the strengthening system. Table 3 shows that the maximum reaction force for Beam-SS-3EB and Beam-SS5EB were $30.30 \mathrm{kN}$ and $31.77 \mathrm{kN}$, respectively, represents an increase of $17.67 \%$ and $23.29 \%$ compared to that of the Beam-CS.

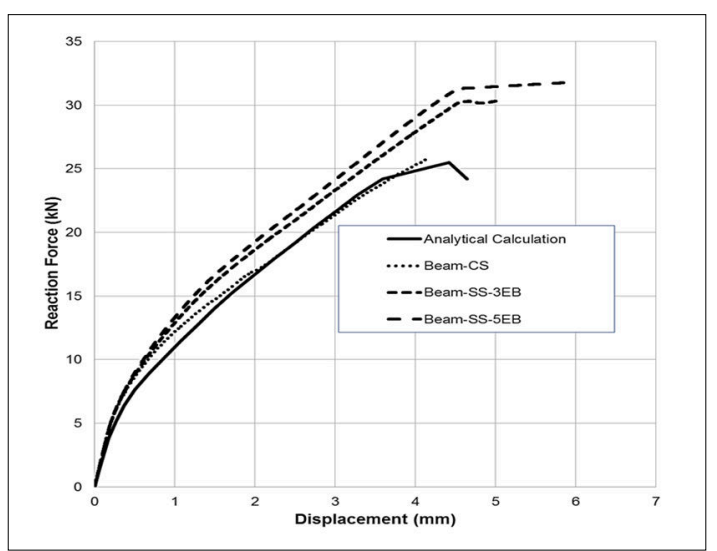

Fig. 9. Comparison of load-displacement response of control specimen and strengthened specimens

It is evidence that the embedded bars installed on the specimen did not significantly affect the stiffness of the strengthened beams at early stages of loading where the cracks on the concrete did not existed. On this stage of loading, the load acting on the specimens resisted by the concrete itself. Further loading would cause cracks since the ability of concrete to resist tensile load exceeded and this load was transferred to the embedded reinforcing bars. Figure 9 also shows that the control specimen failed in shear; it can be seen from the load-displacement curve of the specimen that when the maximum shear capacity was reached the load dropped all of a sudden. While for the strengthened specimens, as the loads were increased beyond the shear capacity of the specimen, the beam structures were able to withstand load by transferring it to the flexural reinforcement. As a result, both strengthened specimens failed in combination of shear and flexural failure.

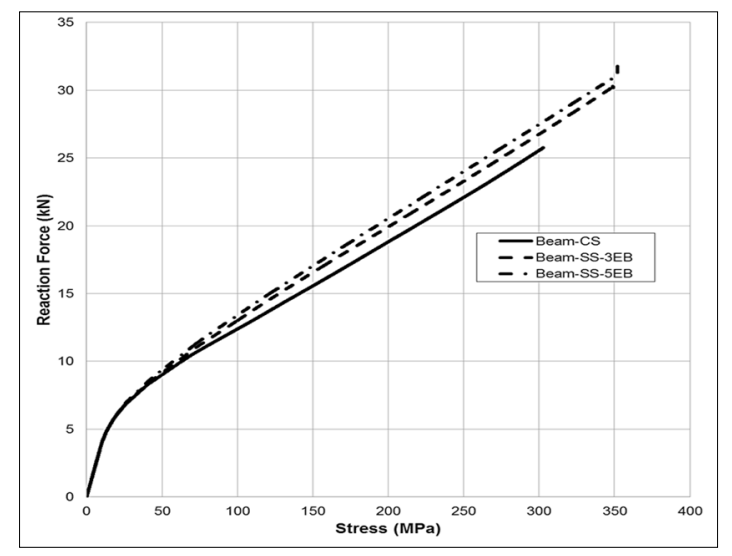

Fig. 10. Comparison of Stress response of control specimen and strengthened specimens

The stress responses of the bottom longitudinal reinforcement bars is depicted in Figure 10. During the early stage of loading, there were no difference of the stress responses of the flexural reinforcement among the three 
specimens. At this stage, loads were fully retained by the concrete element. As the load was increasing, the stress response of the flexural reinforcement of both strengthened specimens was also increasing. It can be concluded that the embedded reinforcement steel bars provided additional strength to the specimens by distributing the forces on the shear span.

\section{CONCLUSIONS}

This paper conducted the study of behaviour of unstrengthened and strengthened reinforced beam by using deep embedment method through a 3D finite element model. Based on the results, the following conclusions can be drawn:

1. Element size significantly affected the load-displacement curve behaviour. In this study, FE analysis results for 25 $\mathrm{mm}$ element size gave a better prediction. The similarity of the hysteresis curve in the FE analysis using the $25 \mathrm{~mm}$ element size suggested a reasonably good agreement between the analytical calculation and the prediction result from the FE analysis.

2. Maximum reaction force for both strengthened beams was enhanced with the increase of embedded bars installed. Maximum reaction force for Beam-SS-3EB and Beam-SS-5EB were $30.30 \mathrm{kN}$ and $31.77 \mathrm{kN}$, respectively, represents an increase of $17.67 \%$ and $23.29 \%$ compared to that of the Beam-CS.

\section{AUTHOR INFORMATION}

\section{Corresponding Author}

*Email: ridwan@eng.unri.ac.id

\section{ORCID}

Ridwan : 0000-0002-4582-0251

\section{REFERENCES}

[1] Chaallal O, Nollet MJ, Perraton D. Strengthening of reinforced concrete beams with externally bonded fiber -reinforced-plastic plates: design guidelines for shear and flexure. Canadian Journal of Civil Engineering. 1998;25(4):692-704.

[2] Pellegrino C, Modena C. Fiber Reinforced Polymer Shear Strengthening of Reinforced Concrete Beams with Transverse Steel Reinforcement. J Compos Constr. 2002;6(2):104-11.

[3] Abdelhak B, Omar C. Shear Strengthening Reinforced Concrete Beams with Fiber-Reinforced Polymer: Assessment of Influencing Parameters and Required Research. Aci Struct J. 2004; 101(2).

[4] Laura De L, Antonio N. Shear Strengthening of Reinforced Concrete Beams with Near-Surface Mounted Fiber-Reinforced Polymer Rods. Structural Journal. 2001;98(1).

[5] Barros JAO, Dias SJE. Near surface mounted CFRP laminates for shear strengthening of concrete beams. Cement and Concrete Composites. 2006;28(3):27692.

[6] Dirar S, Lees JM, Morley CT. Precracked Reinforced Concrete T-Beams Repaired in Shear with Prestressed
Carbon Fiber-Reinforced Polymer Straps. Aci Struct J. 2013;110(5):855-65.

[7] Valerio P, Ibell TJ. Shear strengthening of existing concrete bridges. Proceedings of the Institution of Civil Engineers - Structures and Buildings. 2003;156(1):7584.

[8] Valerio P, Ibell TJ, Darby AP. Deep Embedment of FRP for Concrete Shear Strengthening. P I Civil Eng-Str B. 2009;162(5):311-21.

[9] Ridwan R, Dirar S, Jemaa Y, Yang J, Elshafie M. Shear strengthening of exterior beam-column joints using embedded carbon fibre reinforcement polymer bars. In: Lees J, Keighley S, editors. Advanced Composites in Construction; 9-11 September 2015; University of Cambridge, St John's CollegeCambridge; United Kingdom. United Kingdom: NetComposites Limited; 2015. p. 148-53.

[10] Ridwan R, Dirar S, Jemaa Y, Theofanous M, Elshafie M. Experimental Behavior and Design of Exterior Reinforced Concrete Beam-Column Joints Strengthened with Embedded Bars. J Compos Constr. 2018;22(6):04018047.

[11] Qapo M, Dirar S, Yang J, Elshafie MZEB. Nonlinear finite element modelling and parametric study of CFRP shear-strengthened prestressed concrete girders. Constr Build Mater. 2015;76:245-55.

[12] Bentz EC. Sectional Analysis of Reinforced Concrete Members: University of Toronto; 2000.

[13] Lubliner J, Oliver J, Oller S, Onate E. A Plastic-Damage Model for Concrete. Int J Solids Struct. 1989;25 (3):299-326.

[14] Lee JH, Fenves GL. Plastic-Damage Model for Cyclic Loading of Concrete Structures. J Eng Mech-Asce. 1998;124(8):892-900.

[15] Abaqus. ABAQUS analysis : user's manual. Providence, Rhode Island: ABAQUS Inc.; 2008.

[16] Carreira D, J, Chu K-H. Stress-Strain Relationship for Plain Concrete in Compression. Journal Proceedings. $1985 ; 82(6)$.

[17] CEB-FIP. Comité Euro-International du Béton- Fédération Internationale de la Précontrainte (CEB-FIP) model code 1990. Lausanne, Switzerland: Comite Euro-International du Beton; 1993. 437 pp p.

[18] Kratzig WB, Polling R. An elasto-plastic damage model for reinforced concrete with minimum number of material parameters. Comput Struct. 2004;82 (15-16):1201-15.

[19] Wight JK, MacGregor JG. Reinforced Concrete: Mechanics and Design: Pearson Prentice Hall; 2009.

[20] Bažant Z, Oh BH. Crack band theory for fracture of concrete. Mat Constr. 1983;16(3):155-77.

[21] Feenstra PH. Computational aspects of biaxial stress in plain and reinforced concrete. Delft: Delft University Press; 1993.

[22] Birtel V, Mark P, editors. Parameterised finite element modelling of RC beam shear failure. Proceedings of the 19th Annual International ABAQUS Users' Conference Boston:[sn]; 2006.

[23] Gebreyohaness AS. Seismic Assessment of Pre-1936 Dual RC Wall-Riveted Steel Frame Buildings: 
University of Auckland; 2013.

[24] Danesh F, Esmaeeli E, Alam MF. Shear Strengthening of 3D RC Beam-Column Connection Using GFRP: FEM Study. Asian Journal of Applied Sciences. 2008; 1:217-27.

[25] Abbas AA, Mohsin SMS, Cotsovos DM. Seismic response of steel fibre reinforced concrete beam-column joints. Eng Struct. 2014;59:261-83. 